\title{
The study of the causal relationship between innovativeness and entrepreneurial intention among undergraduate students
}

\author{
Narubodee Wathanakom ${ }^{*}$ (D), Jintavee Khlaisang and Noawanit Songkram
}

\author{
* Correspondence: narubodee@ \\ gmail.com \\ Faculty of Education, Chulalongkorn \\ University, Bangkok, Thailand
}

\begin{abstract}
In recent years, entrepreneurs have become key drivers of business growth worldwide, since that time, entrepreneurial education has subsequently been garnering an increased level of interest. Entrepreneurship is considered to be a combination of both art and science, used to create value when targeting customers; however, there appears to be a myth when it comes to the recipe required for success. It was discovered by The Office of Small and Medium Enterprise Promotion that less than $10 \%$ of Thai small and medium entrepreneurial businesses were successful, while the global rate of success is close to 5 times higher than that of Thailand. Therefore, a better understanding of key success factors is necessary going forward. Typically, an entrepreneur's journey starts with entrepreneurial intention, opportunity recognition, business initiative creation, and resource assembly, if they are to start their venture successfully. Entrepreneurial intention is a prerequisite to entrepreneurial behavior, based on the theory of planned behavior. Subsequently, scholars are interested in the key factors which drive entrepreneurial intention. While innovativeness has been proven to be one of the critical factors within certain groups of the population, there is little empirical data on the causal relationship between innovativeness and entrepreneurial intention amongst undergraduate students. As such, this study has two main objectives: (1) to explore factors influencing innovativeness, attitudes towards entrepreneurship and the entrepreneurial intentions of undergraduate students, and (2) to understand the causal relationship between innovativeness and entrepreneurial intentions among undergraduate students. The population of the study is comprised of undergraduate students from public universities and 330 effective responses were received in the survey. Based on the findings from confirmatory analysis and multiple regression, the empirical data is consistent with the theoretical measurement model for both innovativeness and entrepreneurial intention and (2) innovativeness can effectively predict entrepreneurial intention among undergraduate students.
\end{abstract}

Keywords: Entrepreneurial intentions, Innovativeness, Entrepreneurial attitude 


\section{Introduction}

Interest in entrepreneurial education has been increasing ever since entrepreneurs became one of the key drivers of business growth worldwide (Bhat \& Singh, 2018; Munawaroh, 2018; Yıldırım, Trout, \& Hartzell, 2019). Entrepreneurship has been used as a weapon for developed countries to battle economic downturn (Ylldırım et al., 2019). In addition, small and medium enterprises contribute $90 \%$ towards total global business (Office of Small and Medium Enterprise Promotion and Policy, 2018). In developed countries, small and medium enterprises contribute more than 50\% of the GDP (Gross Domestic Products) and generate more than $65-70 \%$ of total employment (Office of Small and Medium Enterprise Promotion and Policy, 2018). Due to this, the competitiveness of developed countries does not depend upon large corporations anymore, but rather on small- and medium-sized corporations which have the ability to rejuvenate business growth through innovation, productivity and employment. Currently, the Thai economy is undergoing a recession as consumers are cautious about their household spending, which is evident from the declining sales of convenience stores (The Bank of Thailand, 2018). As a result, competition in the market has been made more severe; meaning that each corporation, whether large or small, is focusing on establishing an innovative and unique proposition by which they mean to gain a competitive advantage over others. In response to this, the Thailand 4.0 policy was launched by the Thai government with the aim of transforming the economy from being efficiency driven to one driven by innovation and creativity (Office of Small and Medium Enterprise Promotion and Policy, 2018). One of the factors which allows entrepreneurial education to be successful is the interrelationship driven by the triple helix model (government-industryuniversity); this can be observed in the USA and China, where support from their respective governments and industries has led to the success of entrepreneurial education. In other words, there has always been a focus on higher education ( $\mathrm{Yu}, 2018)$.

The Office of Small and Medium Enterprise Promotion identified that less than 10\% of Thai small and medium entrepreneurs were successful while the global rate of success is close to 5 times higher than that of Thailand (Office of Small and Medium Enterprise Promotion and Policy, 2018). Thailand has a high entrepreneurial intention rate at $31 \%$, while the USA and UK have only one-third of this. The reason for this being that in these countries, entrepreneurs equate to symbols of success, and media attention rate for entrepreneurship is the highest in the world at 87\% (Bosma \& Kelley, 2019). Total early-stage entrepreneurial activity (TEA) in Thailand is at $20 \%$, the highest in East and South Asia, and higher than the European and North American regions, for example, the USA is at $16 \%$ and the rate in the UK is lower than 10\% (Bosma \& Kelley, 2019). This is because business in Europe and North America is highly competitive for newcomers when trying to begin a new venture, and there are other job options available (Bosma \& Kelley, 2019). Regarding gender differences, Thailand has an equal rate of males and females in early-stage entrepreneurship, while in the US and UK, there is a significantly higher number of males than females (Bosma \& Kelley, 2019). In terms of educational background, more Thai women than Thai men started new ventures hold bachelor's degrees and have progressed through higher education, which tends to lead to better business innovation (Guelich, 2018). The proportion of innovative early-stage entrepreneurship in Thailand is at $4 \%$, while in Canada and the USA are at $8 \%$ and $6 \%$, respectively. This signifies the need in Thailand to boost innovation 
among entrepreneurs, driving the competitive advantage, and improving upon the rate of success (Bosma \& Kelley, 2019).

During the past 3 years, Thai universities have been promoting entrepreneurial education and startup communities in order to foster creative thinking and entrepreneurial attitudes. An example of this would be at Thammasat University, which has a vision in which they would like to transform themselves into an entrepreneurial university and create a startup district within the campus. Mahidol University recommends that each corporation incorporates an entrepreneurial mindset and creativity as core competencies when recruiting and developing employees for human resources positions, again in an effort to increase their competitive advantage. This demonstrates that Thai universities are emphasizing the importance of driving entrepreneurial education.

The Office of Thai Small and Medium Enterprise conducted a study in 2015 and found out that $90 \%$ of small and medium entrepreneurs' products or services are indifferent to pre-existing products in the market, demonstrating a lack of uniqueness (Office of Small and Medium Enterprise Promotion and Policy, 2018). Only a few entrepreneurs exist who have the ability to develop innovative, new products. As innovativeness is closely linked to entrepreneurship and they complement each other, therefore, it is especially noteworthy to explore the factors which impact innovativeness and entrepreneurial intention, including the causal relationship between innovativeness and entrepreneurial intention. It was mentioned by Schumpeter (1934) cited in Yıldırım et al., 2019 that creativity or innovativeness is part of entrepreneurship because it involves opportunity recognition, idea generation, and innovation. Here, creativity refers to the creation of new ideas (Amabile, 1996; Ames and Runco, 2005 cited in Ylldırım et al., 2019). Therefore, an opportunity is presented to establish an understanding of the relationship between innovativeness and entrepreneurial intention, as well as the indicators of each variable.

\section{Literature review}

\section{Definition of entrepreneur}

Entrepreneurship is defined as the process by which an individual recognizes an opportunity through the method of considering both controllable and uncontrollable resources (Bygrave \& Zacharakis, 2011). Within entrepreneurship lies the core concept of the identification of opportunities and bringing new ideas to life (Burns, 2014). This can be achieved by an individual or a group of individuals, as long as they possess creativity, passion, and a risk-taking mindset. Entrepreneurship can be present in one's own business or within an established organization, the latter being referred to as corporate entrepreneurship (Barringer \& Ireland, 2012). Longenecker, Moore, and Petty (2003) defined entrepreneurship as when a person discovers needs which exist in a market and starts a new venture in order to address said needs, then gaining revenue, profits, and social recognition. In addition, entrepreneurs will often face new challenges head on while managing the risks of the ever-changing conditions of an economic environment. It was written by Mayer (2004) that an entrepreneur is one who integrates multiple resources to drive business growth by developing new ideas of their own origin, alongside the use of experiences and learnings of prior partnerships. 
Thai scholars also defined entrepreneurs in the Thai context. Smithikrai (2005) stated that an entrepreneur is an individual, or group of individuals, who set up and manage their own ventures with freedom and risks to conduct business with the aim of reaching a target revenue and profit. An entrepreneur was defined by Rumakom (2001) as an individual, or group of individuals, which are important to a capitalist economy as they produce ideas, innovations, and new business opportunities. They also collect funding to create businesses, manage businesses, and deliver products and/or services to the public. As such, it can be concluded that an entrepreneur is a person who creates business, while accepting the potential risks of doing so, and searches for business opportunities to create products or services which are used to target customers and return profits to the entrepreneurs themselves.

Therefore, it can be concluded that entrepreneurs are people who are inspired to look for opportunities in which they can utilize their creativity to make a difference in a business. They do this with the intention of starting a new venture and managing it to success through the use of consolidated knowledge and experiences, in addition to managing calculated risks.

\section{The characteristics of entrepreneurs}

Covin and Slevin (1990) outline three important characteristics of entrepreneurs: (1) innovativeness (2) risk taking, and (3) proactiveness.

Knight (2000) mentions the two core characteristics of an entrepreneur as innovativeness and proactiveness, and Lumpkin and Dess (1996) conducted research which defined five key characteristics of entrepreneurs: innovativeness, risk taking, proactiveness, competitive aggressiveness, and autonomy (Table 1).

Koyviriyakul (2016) studied the key factors affecting entrepreneurial intention, and these include an attitude toward startup entrepreneurs, innovativeness, self-efficacy, perceived opportunity, passion for startup businesses, job satisfaction, government policies, and financial support. It was found that innovativeness, passion for startup business, job satisfaction, and perceived opportunity were key factors which contributed towards entrepreneurial intention.

Creativity or innovativeness is related to entrepreneurship as it is regarded as one of the most important key success factors for entrepreneurs and plays a critical role in the entrepreneurial process (Melati, Arief, \& Baswara, 2018). Innovativeness must be used

Table 1 The definition of entrepreneurial characteristics (Lumpkin \& Dess, 1996)

\begin{tabular}{ll}
\hline Entrepreneurial characteristics & Definition \\
\hline Innovativeness & $\begin{array}{l}\text { An intention to introduce new product or services, driven by creativity, } \\
\text { trial, process, and use of the latest technology. }\end{array}$ \\
Risk taking & $\begin{array}{l}\text { A decision with strong determination under uncertainties, e.g., decision } \\
\text { to invest in markets or loans, then used to invest in a new venture }\end{array}$ \\
Proactiveness & $\begin{array}{l}\text { A forward-looking attitude for new business opportunities, e.g., new a } \\
\text { product or service design, even in a competitive environment, as well } \\
\text { as ways to transform the business }\end{array}$ \\
Competitive aggressiveness & $\begin{array}{l}\text { A proactive attempt to face severe competition and an ability to } \\
\text { counteract well to create a competitive business advantage }\end{array}$ \\
Autonomy & The freedom of an individual or a group to make decisions and to \\
& push forward new business concepts, practically applying them in real life
\end{tabular}


by entrepreneurs to identify solutions, tackle daily problems, and generate new products or services (Dimov, 2007; Ward, 2004 cited in (Melati et al., 2018).

\section{The theory of planned behavior}

Both the social and individual characteristics of entrepreneurs are considered by the theory of planned behavior. This means that attitudes, characteristics, and social backgrounds influence an intention which will develop into a behavior (Ajzen, 2002 cited in Bhat \& Singh, 2018). This theory has previously been used in the retail business research in explaining the buying patterns of shoppers, which are driven by purchase intentions. The intention to purchase is driven by three components: subjective norms, attitudes, and perceived behavior. This relates to the context of entrepreneurial intention in that attitudes towards entrepreneurial characteristics and perceived behaviors are predictors of entrepreneurial intention (Ajzen, 1991 and 2002 cited in Bhat \& Singh, 2018). Furthermore, family background, which is included as part of the social background, also has an influence on the entrepreneurial intention. Entrepreneurial intention is the result of the interaction amongst three components, which can all be shaped by the learning process (Iglesias-Sánchez, Jambrino-Maldonado, \& de las HerasPedrosa, C., 2019). In this study, we are interested in innovativeness and attitudes towards entrepreneurship as these are core personality traits and have thus far been underexplored in the Thai context.

In order to promote an entrepreneurial education curriculum, there is a need to understand factors or characters that are highly influenced by entrepreneurial intention and could predict the level of intention. This will aid instructional designers, lecturers, and subject matter experts in designing the applicable method of instruction more effectively and efficiently.

This study has arisen from the following research questions:

1. What are the factors influencing innovativeness, attitudes towards entrepreneurs, and entrepreneurial intentions among undergraduate students?

2. Is there a causal relationship between innovativeness and entrepreneurial intentions among undergraduate students?

In order to address the research questions, there are three research objectives:

1. To explore indicators influencing innovativeness and entrepreneurial intentions among undergraduate students

2. To study the causal relationship between innovativeness and entrepreneurial intentions among undergraduate students

3. To recommend future entrepreneurial education opportunities to undergraduate students

\section{The scope of this study}

1. The population of this study was made up of undergraduate students from public universities in Bangkok. The sample size was obtained through the use of multi- 
stage sampling, ranging from simple random sampling of public universities in Bangkok, to accidental sampling, allowing us to acquire a total sample 330 students and enabling us to meet the requirements of confirmatory factor analysis. Pinyo (2012) recommends the following sampling size calculation method/criterion for factor analysis. For this study, there were total 15 questions used for factor analysis, with the minimum requirement being a sample of 150-200 participants; however, a total sample of 330 participants was used in order to ensure a more accurate representation of the population (Table 2).

2. In terms of research variables, the independent variables are innovativeness and attitudes towards entrepreneurship, while the dependent variable is the entrepreneurial intentions of undergraduate students. A self-administered questionnaire was used, which was comprised of four sections: (1) respondent demographics, (2) attitudes towards entrepreneurship, (3) innovativeness, (4) entrepreneurial intention with a 5-point Likert scale response for sections "Literature review", "Methods", and "Results".

3. The questionnaire was validated with 50 respondents to validate its internal consistency with Cronbach Alpha, and it was found that the Cronbach Alpha score of questionnaires for three factors is as follows: innovativeness had a score of 0.767 , attitudes towards entrepreneurship had a score of 0.713, and entrepreneurial intention had a score of 0.879 . The overall questionnaire had a Cronbach Alpha score of 0.871 .

4. The study was analyzed by descriptive statistics, confirmatory factor analysis, and multiple regression.

\section{Expected research benefits}

It is expected that we will be able to understand the factors and/or indicators of innovativeness, entrepreneurial attitude, and the entrepreneurial intentions of undergraduate students in a Thai context, and to discover which can lead to better recommendations. The purpose being to enhance entrepreneurial competency among university graduates and produce higher quality human resources supplied in Thailand.

\section{Research framework}

The review of literature and previous research enabled the creation of a research framework with a focus on individual factors, leading to entrepreneurial intentions (Fig. 1).

Table 2 Sample size criterion of confirmatory factory analysis

\begin{tabular}{|c|c|}
\hline Method/techniques & Sample size criterion \\
\hline $\begin{array}{l}\text { 1. How to define the number of samples for factor analysis } \\
\text { (Tabachnick and Fidell, 2011) cited in (Pinyo, 2012) }\end{array}$ & $\begin{array}{l}\text { 1) } 50 \text { respondents: very bad } \\
\text { 2) } 100 \text { respondents: bad } \\
\text { 3) } 200 \text { respondents: acceptable } \\
\text { 4) } 300 \text { respondents: good } \\
\text { 5) } 500 \text { respondents: very good }\end{array}$ \\
\hline 2. Rule of thumb & 300 samples \\
\hline $\begin{array}{l}\text { 3. How to define the number of samples for factor analysis } \\
\text { based on the number of questions or sets of items } \\
\text { (Dawson and Trapp, } 2001 \text { cited in Pinyo, 2012) }\end{array}$ & $\begin{array}{l}\text { The sample size for factor analysis should be } \\
10 \text { times of the total number of questions }\end{array}$ \\
\hline
\end{tabular}




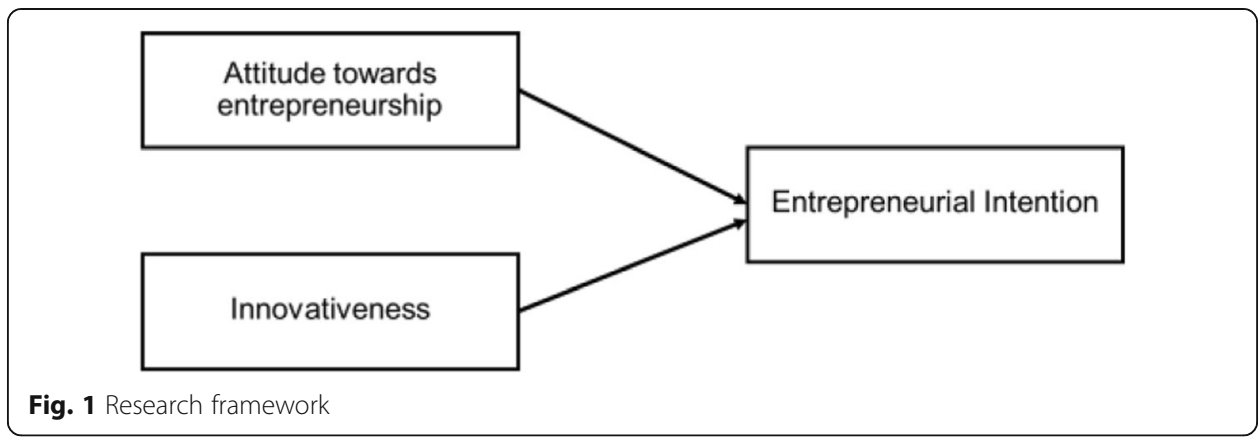

\section{Methods}

The population of this study consisted of undergraduate students from public universities located in Bangkok. Multi-stage sampling was used to obtain the sample size, starting with simple random sampling of public universities in Bangkok, then moving onto accidental sampling in order to choose a total sample number of 330 students, which met the requirement of confirmatory factor analysis. Pinyo (2012) recommended this sampling size calculation method/criterion for factor analysis. During this study, there were a total of 15 questions used for factor analysis, and the minimum requirement is 150-200 samples; however, a total of 330 samples were collected to ensure a good representation of the population. The study was analyzed using descriptive statistics, confirmatory factor analysis, and multiple regression.

\section{Results}

This study aims to uncover (1) factors influencing innovativeness, attitudes towards entrepreneurship, and the entrepreneurial intention of undergraduate students, and (2) the causal relationship between innovativeness and entrepreneurial intention among undergraduate students. The data was analyzed using descriptive statistics, confirmatory factor analysis, and multiple regression.

Table 3 Demographic information of respondents

\begin{tabular}{lcc}
\hline General information & Total (330 respondents) & Percentage \\
\hline Gender & 48 & 14.50 \\
Male & 282 & 85.50 \\
Female & & 3.60 \\
Age (mean = 20.18 years old, SD =0.79) & 12 & 9.10 \\
18 years old & 30 & 56.40 \\
19 years old & 186 & 27.30 \\
20 years old & 90 & 3.60 \\
21 years old & 12 & \\
22 years old & & 54.55 \\
Does your family own a business? & 180 & 45.45 \\
Yes & 150 & \\
No & 156 & 47.30 \\
Have you ever attended entrepreneurial classes before? & 52.70 \\
Yes & 174 & \\
No & & \\
\hline
\end{tabular}




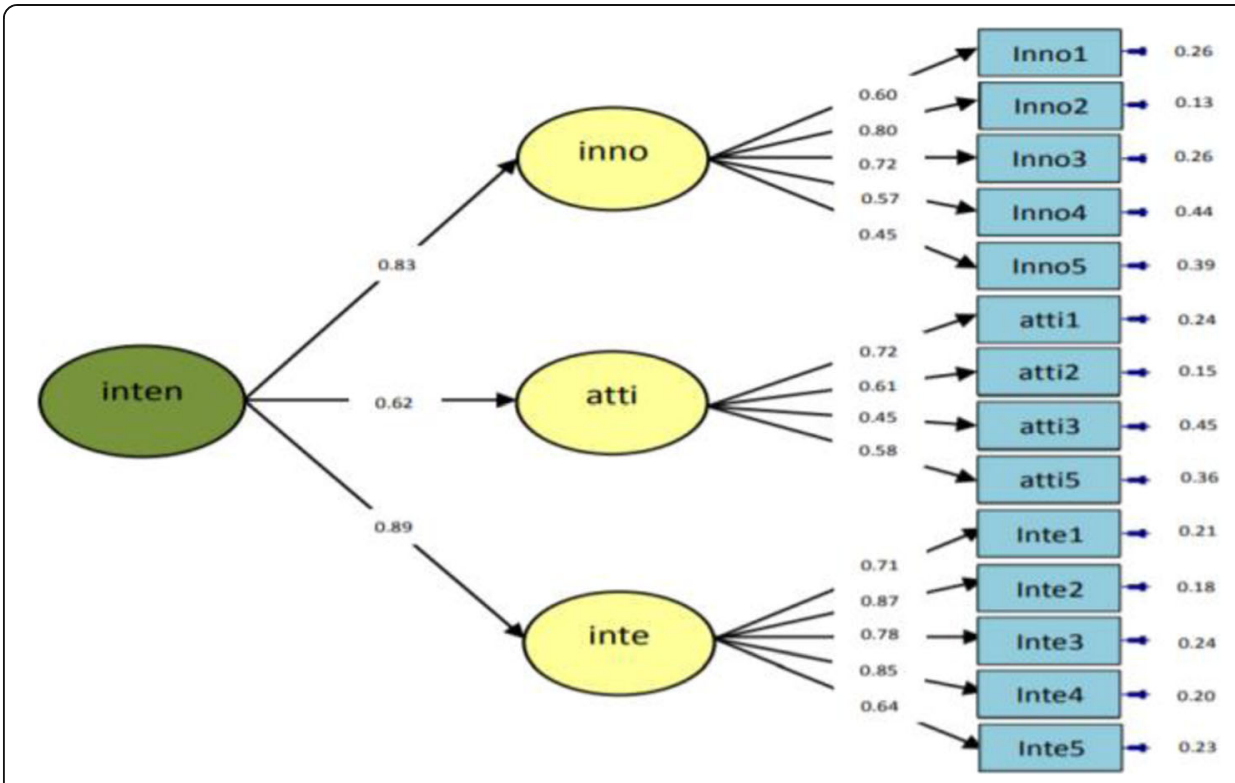

Fig. 2 Indicators/factors influencing entrepreneurial intention

\section{Demographic information}

Most of the respondents were female undergraduate students (85.5\%). The average age was 20.18 years old. The majority was 20 years old (56.1\%), followed by 21 years old (27.3\%). More than half of them were from entrepreneurial families $(54.55 \%)$ and had never taken any entrepreneurial classes before (52.7\%) (Table 3).

Confirmatory factory analysis for innovativeness, attitude towards entrepreneurship and entrepreneurial intention

Figure 2 depicts the model for second-order confirmatory factory analysis (SCFA), which is the technique used to confirm factors from theoretical framework. On the far left is the second order, which has factor loading from 0.62 to 0.89 , and the next one is the first-order factor. Within each factor, there are indicators which show factor loading from 0.45 to 0.87 (Table 4).

The total number of indicators for the first-order factor was 14 questions: (1) innovativeness had 5 questions and showed factor loading of indicators from 0.45 to 0.80 and inno2 had highest at 0.9 , while (2) attitudes towards entrepreneurship had 4 questions

Table 4 Confirmatory factory analysis results for three factors

\begin{tabular}{llll}
\hline Questions & Factor loading & \\
\cline { 2 - 4 } & Factor 1: innovativeness (inno) & $\begin{array}{l}\text { Factor 2: attitude towards } \\
\text { entrepreneurship (atti) }\end{array}$ & $\begin{array}{l}\text { Factor 3: entrepreneurial } \\
\text { intention (inte) }\end{array}$ \\
\hline No. 1 & $0.60^{*}$ & $0.72^{*}$ & $0.74^{*}$ \\
No. 2 & $0.80^{*}$ & $0.61^{*}$ & $0.87^{*}$ \\
No. 3 & $0.72^{*}$ & $0.45^{*}$ & $0.78^{*}$ \\
No. 4 & $0.57^{*}$ & & $0.85^{*}$ \\
No. 5 & $0.45^{*}$ & $0.58^{*}$ & $0.64^{*}$ \\
\hline
\end{tabular}

$X^{2}=169.72, \mathrm{df}=56, P=0.000, X^{2} / \mathrm{df}=3.03, \mathrm{RMSEA}=0.08, \mathrm{SRMR}=0.06, \mathrm{TLI}=0.91, \mathrm{CFI}=0.94$ 
Table 5 Correlation coefficient matrix of innovativeness, attitude towards entrepreneurship, and entrepreneurial intention among undergraduate students

\begin{tabular}{llll}
\hline Variable/factor & Innovativeness & $\begin{array}{l}\text { Attitude towards } \\
\text { entrepreneurship }\end{array}$ & $\begin{array}{c}\text { Entrepreneurial } \\
\text { intention }\end{array}$ \\
\hline Innovativeness & 1.00 & - & - \\
Attitude towards entrepreneurship & $0.31^{*}$ & 1.00 & - \\
Entrepreneurial intention & $0.60^{*}$ & $0.45^{*}$ & 1.00 \\
\hline${ }^{*} P<0.05$ & & &
\end{tabular}

with factor loading from 0.45 to 0.72 with att1 having the highest at 0.72 , and (3) entrepreneurial intention had 5 questions with factor loading from 0.64 to 0.87 with inte2 had the highest at 0.87 . This model is considered to be a good fit with the theoretical model for sample size $>250$, and a significant $P$ value is expected (Hair, Black, Babin, Anderson, \& Tatham, 2006)

\section{Correlation coefficient of innovativeness, attitude towards entrepreneurship and entrepreneurial intention}

It was revealed in the study that there was correlation between each variable, producing a significance level 0.05 . The two variables which have highest correction are innovativeness and entrepreneurial intention $(r=0.60)$, followed by attitudes towards entrepreneurship and entrepreneurial intention $(r=0.45)$, while attitude towards entrepreneurship and innovativeness had the lowest correlation $(r=0.31)$. After considering the appropriateness of using the data to conduct multiple regression, the correlation coefficient should not be higher than 0.85 , as this can lead to multi-collinearity. From the correlation results, it can be seen that there is no correlation coefficient score higher than 0.85 . Therefore, it is possible to further analyze those three variables with multiple regression (Table 5).

\section{Multiple regression to analyze the causal relationship among three variables/factors}

According to the stepwise multiple regression of variables, which was used to predict entrepreneurial intention among undergraduate students, it was revealed that innovativeness and attitude towards entrepreneurship are able be used to collectively predict entrepreneurial intention at $44 \%$, with a significance level $0.05(F=64.20)$ (Table 6). Innovativeness has the highest effect on entrepreneurial intention among undergraduate students, followed by attitude towards entrepreneurship (Beta $=0.30$ ), and can be summarized using the following formula:

Table 6 Coefficient and ranking of independent variables: innovativeness and attitude towards entrepreneurship affecting dependent variable: entrepreneurial intention among undergraduate students

\begin{tabular}{lllllll}
\hline Dependent variable & \multicolumn{2}{l}{ Unstandardized coefficient } & & $\begin{array}{l}\text { Standardized } \\
\text { coefficient (Beta) }\end{array}$ & $t$ & Sig. \\
\cline { 2 - 3 } & $B$ & SE & & & \\
\hline (Constant) & 0.74 & & & & \\
1. Innovativeness & 0.61 & 0.07 & & 0.51 & .000 \\
2. Attitude towards entrepreneurship & 0.46 & 0.09 & & 0.30 & 4.79 & .000 \\
\hline
\end{tabular}

$R=0.67, R^{2}=0.44$, adjusted $R^{2}=0.44, F=64.20, P$ value $=0.00$ 
Entrepreneurial Intention $=0.74+0.61$ (Innovativeness) +0.46 (Attitude towards entrepreneurship)

\section{Discussions}

As follows are the findings of this study, in accordance with the research questions to be discussed:

1. The five indicators of innovativeness among undergraduate students are (1) constantly participating in new activities, (2) completing actions differently through constant learning from new ideas, (3) continuously searching for technology processes, techniques, or new product ideas, (4) developing creative and unique ideas, and (5) consistently utilizing innovation in real work situations. All indicators significantly affect the factor of innovativeness at the significant level 0.05. The indicator that has the highest factor loading is (2) completing actions differently through constant learning from new ideas, followed by (3) continuously searching for technology processes, techniques, or new product ideas. These two are highly relevant with regard to innovativeness and reflect how entrepreneurs utilize creativity to develop new businesses. This result is consistent with Danish, Asghar, Ahmad, and Ali (2019) who mentioned that there is a significant relationship between openness to change and innovativeness.

2. The five indicators of entrepreneurial intention among undergraduate students are (1) considering the creation of own businesses, (2) being prepared to do anything to become an entrepreneur, (3) trying to initiate and move forward to create own venture, (4) determining to launch own business in the future, and (5) intending to start a new business one day. Each of the indicators is significantly affected by the factor of entrepreneurial intention at significance level 0.05. The indicators that have the highest factor loading are (2) being prepared to do anything to become an entrepreneur, followed by (4) determining to launch own business in the future. This is because those two indicators demonstrate commitment and intention to become an entrepreneur, meaning they are ready to do anything in order to achieve their goal. The entrepreneurial intention among undergraduate students can be created through entrepreneurial education and training (Ayalew, 2020). Therefore, these five indicators should be incorporated in the curriculum of entrepreneurial education.

3. The four indicators of attitude towards entrepreneurship are (1) being an entrepreneur has more advantages than disadvantages, (2) entrepreneurship is interesting, (3) will become entrepreneur if they possess enough resources, and (4) prefers being an entrepreneur to being an employee. The indicator with highest factor loading is (1) being an entrepreneur has more advantages than disadvantages, followed by (2) entrepreneurship is interesting. This is supported by an empirical study concluding that entrepreneurial attitude consists of both affective (feelings or emotions) and cognitive components (rational arguments) (Vasiliki, Chrysostomos, Theodosios, \& Charalampos, 2020).

4. The study adds to the existing knowledge about the causal relationship between innovativeness and entrepreneurial intention even though many of the previous studies mainly mentioned that entrepreneurial passion or attitude towards 
entrepreneurship is the main predictor of entrepreneurial intention (Maziriri, Maramura, \& Nzewi, 2019; Bazan et al., 2019; Doan \& Phan, 2020; Jena, 2020; Nan, Wei, \& Lim, 2020). However, Covin and Slevin (1990) discussed the three key characteristics of entrepreneurship, namely, innovativeness, risk taking, and proactiveness. Syed, Butler, Smith, and Cao (2020) revealed the presence of the mediating effect of innovativeness in the entrepreneurial passion to entrepreneurial intention relationship. Innovativeness can predict entrepreneurial intention among undergraduate students more accurately when compared with attitude towards entrepreneurship. It is also evident in the study by Sharahiley (2020) who reported that innovativeness is the most influential predictor of entrepreneurial intention and behavior. It can be concluded that entrepreneurial education programs in higher education should place high emphasis on innovativeness due to it being an important skill for undergraduate students and leads to entrepreneurial intention in the future.

\section{Future research}

1. This study focused on the two key independent variables affecting entrepreneurial intention: innovativeness and attitude towards entrepreneurship among undergraduate students within Bangkok. Therefore, other factors should be put under investigation with the two existing factors. The scope can be expanded to private universities, as well as across the entire country of Thailand.

2. A study should take place to understand key enablers that can enhance innovativeness among undergraduate students and can then be used to design and improve upon instructions and curriculum for entrepreneurial education.

3. Current problems and barriers experienced by existing entrepreneurs should be investigated, as well as needs assessment for training and education. This would be done to prepare students for the move from university education to real work environments, as well as on the job training programs.

\section{Conclusions}

Based on the findings from the confirmatory analysis and multiple regression, the empirical data is consistent with the theoretical measurement model for both innovativeness and entrepreneurial intention, and (2) innovativeness can effectively predict entrepreneurial intention amongst undergraduate students. Therefore, higher education institutions should promote innovativeness as one of the critical success qualities needed for becoming an entrepreneur in the future. This will have to start with the review of the five processes of instructional design; analysis, design, development, implementation and evaluation.

Acknowledgements

Not applicable

Authors' contributions

All authors read and approved the final manuscript.

Funding

Not applicable 
Availability of data and materials

Not applicable

\section{Competing interests}

All authors declare that they have no competing interests.

Received: 5 December 2019 Accepted: 30 June 2020

Published online: 03 September 2020

\section{References}

Ayalew, M. M. (2020). Bayesian hierarchical analyses for entrepreneurial intention of students. Journal of Big Data, 7(1), 1-23. https://doi.org/10.1186/s40537-020-00293-x.

Barringer, B. R., \& Ireland, R. D. (2012). Entrepreneurship : successfully launching new ventures (4th ed., Global ed. ed.). London: Pearson.

Bazan, C., Datta, A., Gaultois, H., Shaikh, A., Gillespie, K., \& Jones, J. (2019). Effect of the university in the entrepreneurial intention of female students. International Journal of Entrepreneurial Knowledge, 7(2), 26. https://doi.org/10.2478/JEK-20190012.

Bhat, I. H., \& Singh, S. (2018). Analyzing the moderating effect of entrepreneurship education on the antecedents of entrepreneurial intention. Journal of Entrepreneurship Education, 21(1).

Bosma, N., \& Kelley, D. (2019). Global Entrepreneurship Monitor 2018/2019. Retrieved from Chile:

Burns, P. (2014). New venture creation : A framework for entrepreneurial start-ups: Palgrave Macmillan.

Bygrave, W. D., \& Zacharakis, A. (2011). Entrepreneurship (2nd ed. ed.): Wiley.

Covin, J. G., \& Slevin, D. P. (1990). New venture strategic posture, structure and performance: An industry life cycle analysis. Journal of Business Venturing, 5 .

Danish, R. Q., Asghar, J., Ahmad, Z., \& Ali, H. F. (2019). Factors affecting "entrepreneurial culture": The mediating role of creativity. Journal of Innovation and Entrepreneurship, 8(1), 14. https://doi.org/10.1186/s13731-019-0108-9.

Doan, X. T., \& Phan, T. T. H. (2020). The impact of entrepreneurial education on entrepreneurial intention: The case of Vietnamese. Management Science Letters, 10(2020), 10. https://doi.org/10.5267/j.msl.2019.12.040.

Guelich, U. (2018). Global Entrepreneurship Monitor - Thailand Report. Retrieved from Thailand:

Hair, J., Black, W., Babin, B., Anderson, R., \& Tatham, R. (2006). Multivariate data analysis: Pearson prentice hall upper Saddle River.

Iglesias-Sánchez, P. P., Jambrino-Maldonado, C., \& de las Heras-Pedrosa, C. (2019). Training entrepreneurial competences with open innovation paradigm in higher education. Sustainability (Switzerland), 11(17). https://doi.org/10.3390/su11174689.

Jena, R. K. (2020). Measuring the impact of business management Student's attitude towards entrepreneurship education on entrepreneurial intention: A case study. Computers in Human Behavior, 107, 10. https://doi.org/10. 1016/j.chb.2020.106275.

Knight, G. (2000). Entrepreneurship and marketing strategy : The SME under globalization. Journal of international marketing,

Koyviriyakul, K. (2016). The intention of software developers to be startup entrepreneurs, Master of science in management information systems (). Bangkok: Thammasart University.

Longenecker, J. G., Moore, C. W., \& Petty, J. W. (2003). Small business management : An entrepreneurial emphasis (12th ed. ed.): Thomson.

Lumpkin, G. T., \& Dess, G. G. (1996). Clarifying the entrepreneurial orientation construct and linking it to performance. Academy of Management Review, 21.

Mayer, K. E. (2004). How to really create a successful business plan, (4th ed., ). Needham, Massachusetts: Upson Publishing

Maziriri, E. T., Maramura, T. C., \& Nzewi, O. I. (2019). Determinants of Entrepreneurial Intention among Generation Y Students within the Johannesburg Metropolitan Area of South Africa. African Journal of Business \& Economic Research, 14(3), 25. https://doi.org/10.31920/1750-4562/2019/14n3a6.

Melati, I. S., Arief, S., \& Baswara, S. Y. (2018). Does financial background affect entrepreneur students' creativity: An investigation of how rich and poor students start their businesses. Journal of Entrepreneurship Education, 21(1), 1-11.

Munawaroh (2018). The effect of problem-based learning (PBL) method on students critical thinking skills on entrepreneurship practice course (a study on economics education department in the college education and teachers' training PGRI Jombang East Java Indonesia). Journal of Entrepreneurship Education, 1.

Nan, C. J., Wei, L. K., \& Lim, W. L. (2020). Entrepreneurial intention of university graduates: Effect of confucianism. Test Engineering and Management, 83, 5 .

Office of Small and Medium Enterprise Promotion and Policy. (2018). Small and Medium Enterprise Promotion Plan No. 4 (2017-2021). Retrieved from Bangkok:

Pinyo, T. (2012). Confirmatory factory analysis techniques for research. Bangkok: Fernkalaung Printing and Publishing

Rumakom, P. (2001). The management of small business. Bangkok: Physics Center.

Sharahiley, S. M. (2020). Examining entrepreneurial intention of the Saudi Arabia's university students: Analyzing alternative integrated research model of TPB and EEM. Global Journal of Flexible Systems Management, 21(1), 18. https://doi.org/10. 1007/s40171-019-00231-8

Smithikrai, C. (2005). Entrepreneurial potential of Thai University students. Songklanakarin Journal of Social Sciences and Humanities, 11(3), 20.

Syed, I., Butler, J. C., Smith, R. M., \& Cao, X. (2020). From entrepreneurial passion to entrepreneurial intentions: The role of entrepreneurial passion, innovativeness, and curiosity in driving entrepreneurial intentions. Personality and Individual Differences, 157(0191-8869), 6. https://doi.org/10.1016/.paid.2019.109758.

The Bank of Thailand. (2018). Economic Trend Report. Retrieved from https://www.bot.or.th/Thai/MonetaryPolicy/ EconomicConditions/BLP/BLP_TH_Q4\%202018_1aodo79a.pdf 
Vasiliki, V., Chrysostomos, S., Theodosios, P., \& Charalampos, B. (2020). Attitude toward entrepreneurship, perceived behavioral control, and entrepreneurial intention: dimensionality, structural relationships, and gender differences. Journal of Innovation \& Entrepreneurship. https://doi.org/10.1186/s13731-020-0112-0.

Yıldırım, F., Trout, I. Y., \& Hartzell, S. (2019). How Are Entrepreneurial Intentions Affected by Emotional Intelligence and Creativity? Periodica Polytechnica: Social \& Management Sciences, 27(1), 59-65

Yu, C. W. (2018). Understanding the ecosystems of Chinese and American entrepreneurship education.

\section{Publisher's Note}

Springer Nature remains neutral with regard to jurisdictional claims in published maps and institutional affiliations.

Submit your manuscript to a SpringerOpen ${ }^{\odot}$ journal and benefit from:

- Convenient online submission

- Rigorous peer review

Open access: articles freely available online

- High visibility within the field

- Retaining the copyright to your article

Submit your next manuscript at $\boldsymbol{\nabla}$ springeropen.com 